\title{
USING LAME'S PETROPHYSICAL PARAMETERS FOR FLUID DETECTION AND LITHOLOGY DETERMINATION IN PARTS OF NIGER DELTA
}

C. C. Ezeh

(Received 3 March 2014; Revision Accepted 8 July 2014)

\section{ABSTRACT}

This study analyzed seismic and well log data in an attempt to interpret relationship between rock properties and acoustic impedance and to construct amplitude versus offset (AVO) models. The objective was to study sand properties and predict potential AVO classification.

Logs of Briga 84 well provided compressional and shear velocities. AVO synthetic gather models were created using various gas/brine/oil substitutions. The Fluid Replacement Modeling predicted Class 3 AVO responses from gas sands. Log calibrated Lambda Mu Rho (LMR) inversion provided a quantitative extraction of rock properties to clearly determine lithology and fluids. Beyond the standard LMR cross-plotting that isolated gas sand clusters in the log, an improved separation of high porosity sands from shale was also achieved using $\lambda \rho-\mu \rho$ vs. Al. When applied to the calibrated AVO/LMR attributes inverted from 3D seismic, the $\lambda \rho$ analysis permitted a better isolation of prospective hydrocarbon zones than standard Al inversion

Thus, as an exploration tool for hydrocarbon accumulation, the Lambda Mu Rho $(\lambda \mu \rho)$ technique is a good indicator of the presence of low impedance sands encased in shales which are good gas reservoirs.

KEYWORDS: Impedance, synthetic gather, cross-plotting, porosity, inversion

\section{INTRODUCTION}

The study area is situated in the eastern coastal swamp region of the Niger Delta in Nigeria (Fig.1). The regional field structure comprises of large collapsed crest rollover anticline trending east - west and bounded to the north by the central swamp II depobelt.

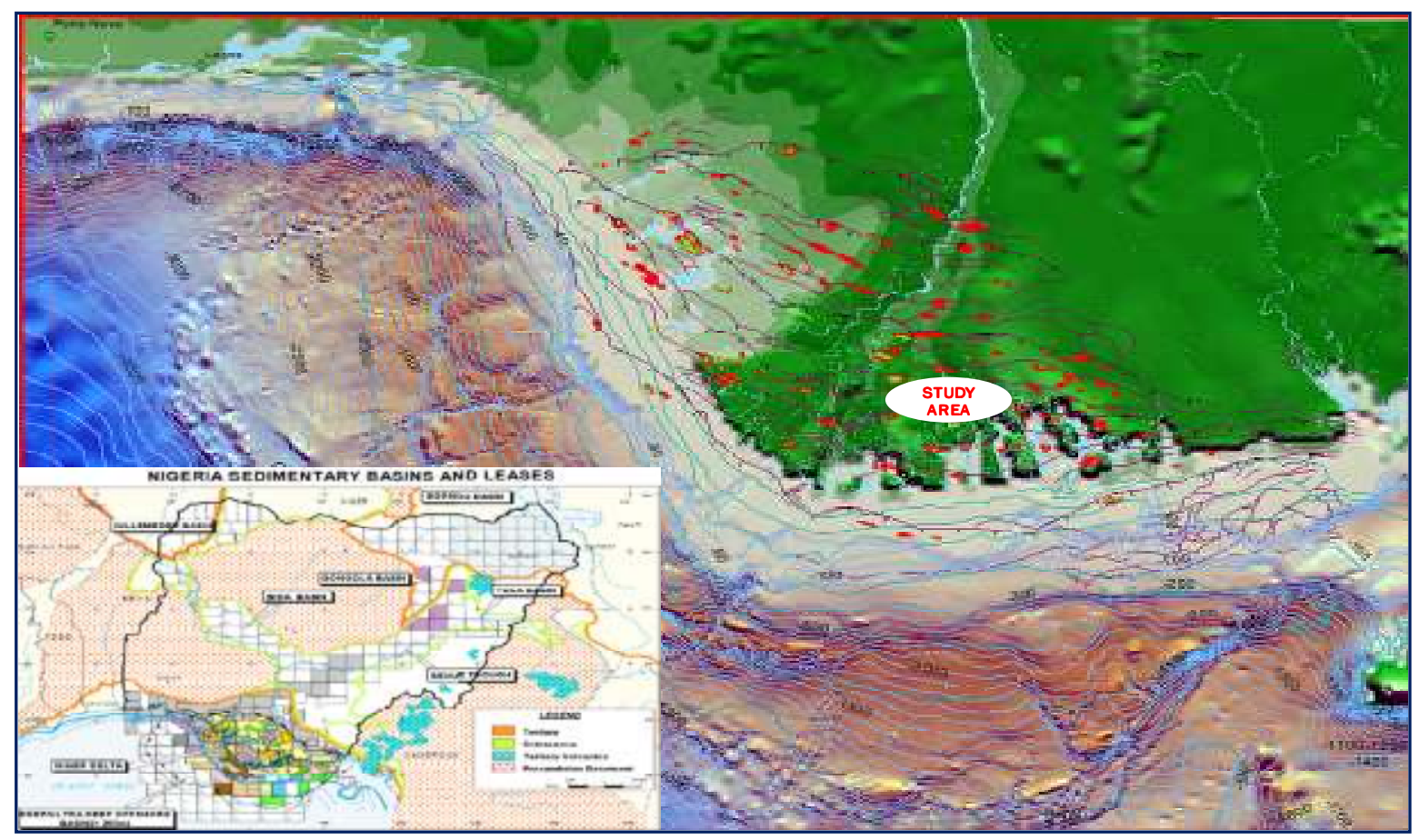

FIG. 1: Map of The Niger Delta showing the location of the study area.

(Modified after Petroconsultants, 1996)

C. C. Ezeh, Department of Geology and Mining, Enugu State University of Science and Technology Enugu, Nigeria 
The motivation for LMR $(\lambda \mu \rho)$ analysis in the study area stems from the failure of the conventional logs to discriminate fluids in the highly porous reservoir sands at depths below $3350 \mathrm{~m}$. Since LMR is a quadratic of impedance, transforming acoustic impedance $(\mathrm{AI})$ and shear impedance (SI) to LMR will increase response sensitivity to any lithology and pore fluid changes. The conversion of velocity measurements to Lamé's moduli parameters of rigidity $(\mu)$ and "incompressibility" $(\lambda)$ offers new understanding into the original rock properties. The Lamé'sparameters $\mu, \lambda$, and $\rho$, which represent "incompressibility", rigidity, and density respectively, allow for enhanced identification of reservoir zones.

Lambda-Mu-Rho (LMR) analysis is one example of how interpreters are using advanced AVO analysis to identify hydrocarbons and reservoir rocks (Goodway et. al., 1997; Gray and Andersen, 2000). LMR analysis, even in the most classic of circumstances, requires cross plotting or the interpretation of multiple volumes of data to correctly interpret lithology and fluids. By using petrophysics to scale the Lambda-Rho $(\lambda \rho)$ and Mu-Rho $(\mu \rho)$ volumes, lithology volumes can be based upon rock properties and AVO. Typically this is done through interactive cross-plot analysis of the LMR volumes.

\section{GEOLOGY}

The Onshore and Continental Shelf Niger Delta are now matured terrains in terms of petroleum exploration and exploitation having been explored and produced for more than half a century now. The three major geological formations namely, Akata, Agbada and Benin Formations define the subsurface of Niger Delta (figure 2).

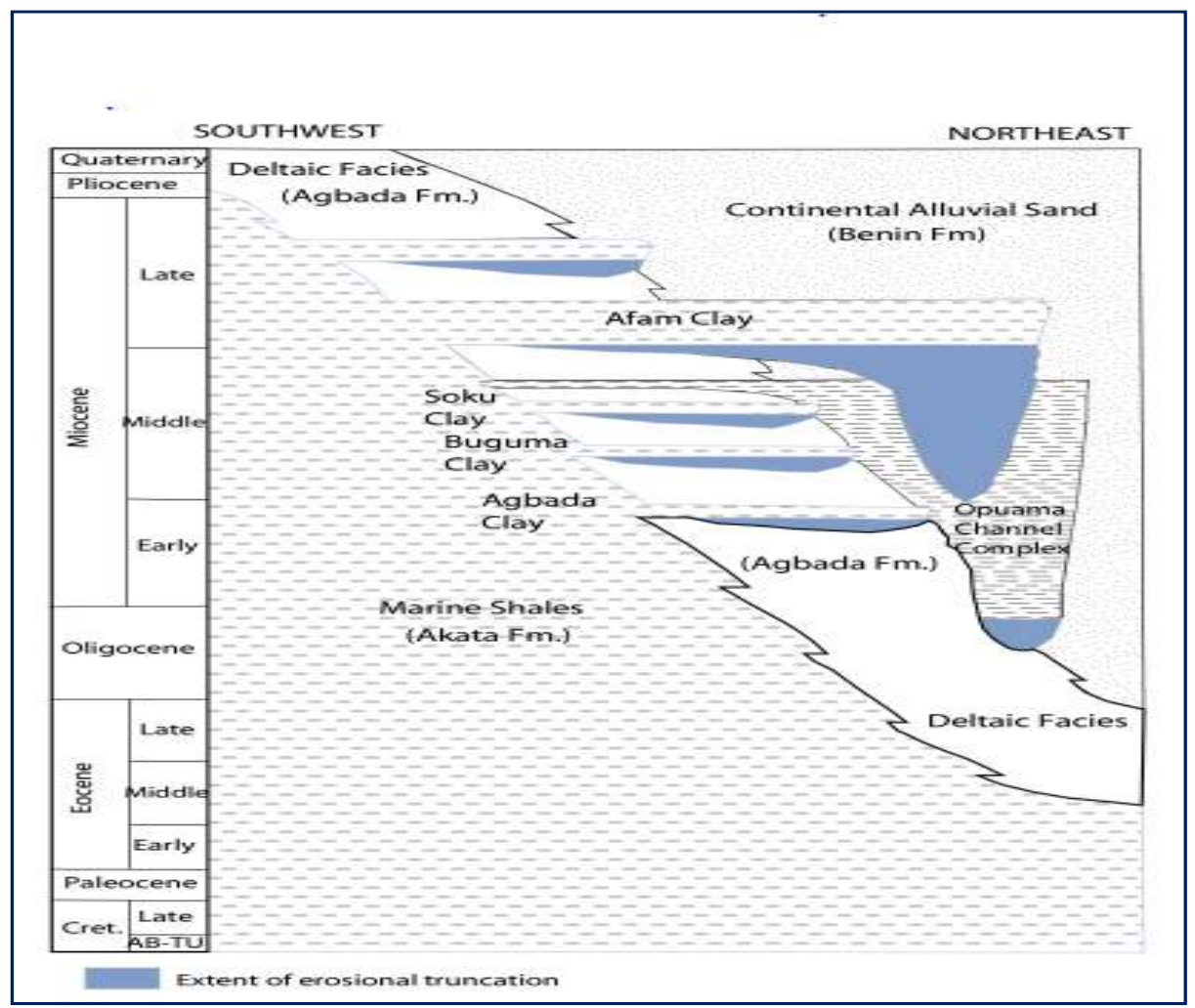

FIG. 2: Stratigraphic column showing three Formations of the Niger Delta. (Tuttle et al, 1999)

The Akata Formation which consists of dark gray shales and silts with rare streaks of sand of probable turbidite flow origin, is estimated to be $6,400 \mathrm{~m}$ thick in the central part of this clastic wedge. Marine planktonic foraminifera suggest a shallow marine shelf depositional setting ranging from Paleocene to Recent in age (Doust and Omatsola, 1990). These shales are exposed onshore in the northeastern part of the delta, where they are referred to as the Imo Shale. This formation also crops out offshore in diapirs along the continental slopes. Where deeply buried, Akata shales are typically overpressured. Akata shales have been interpreted to be prodelta and deeper water deposits that shoal vertically into the Agbada Formation (Stacher, 1995, Doust and Omatsola, 1990).

The Agbada Formation occurs throughout the Niger Delta clastic wedge, has a maximum thickness of about $3,900 \mathrm{~m}$ and ranges in age from Eocene to Pleistocene (Doust and Omatsola, 1990). It crops out in southern Nigeria, where it is called the Ogwashi-Asaba Formation. The lithologies consist largely of alternating sands, silts and shales with progressive upward changes in grain size and bed thickness. The strata are generally interpreted to have formed in fluvial-deltaic environments (Stacher, 1995, Doust and Omatsola, 1990). 
The Benin Formation comprises the top part of the Niger Delta clastic wedge, from the Benin-Onitsha area in the north to beyond the present coastline (Short and Stauble, 1967). The top of the formation is the current subaerially-exposed delta top surface and its base, defined by the top of the youngest underlying marine shales, extends to a depth of about $1400 \mathrm{~m}$. The age of the formation is thought to range from Oligocene to Recent (Short and Stauble, 1967). Shallow parts of the formation are composed entirely of non-marine sands deposited in alluvial or upper coastal plain environments during progradation of the delta (Doust and Omatsola, 1990). The formation thins basinward and ends near the shelf edge.

Most of the Oil and Gas so far discovered and produced to date in the Niger Delta basin have been in the Agbada formation. The Agbada formation is overlain by the continental Benin formation. This formation which is mainly composed of sand units has little petroleum bearing stata.

\section{THEORY}

The approach here is to use modulii/density relationships to velocities $\mathrm{V}$ or impedances I, given as:

$$
\begin{aligned}
& \mathrm{Ip}^{2}=(\mathrm{Vp} . \rho)^{2}=(\lambda+2 \mu) \rho-1 \\
& \text { and } \\
& \mathrm{Is}^{2}=(\mathrm{Vs} . \rho)^{2}=\mu \rho
\end{aligned}
$$

The simple derivations are:

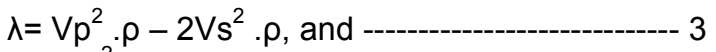

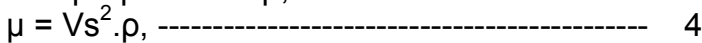

$$
\begin{aligned}
& \text { therefore, }
\end{aligned}
$$

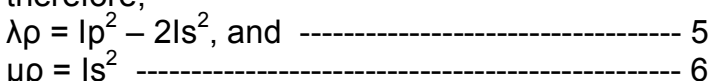

Where $\mathrm{Vp}$, Vs and are compressional and shear wave velocities respectively and $\rho$ is the density.

Goodway et al (1997) demonstrated how LMR analysis can be used to identify gas sands. This comes from the separation in responses of both the $\lambda \rho$ and $\mu \rho$ sections to gas sands versus shales. In some reservoirs, it is possible to separate lithologies at an even finer scale so as to identify wet sands from shales. Paul et al (2001) demonstrate how LMR cross plot analysis can be used for lithology discrimination. They conclude that neither $\lambda \rho$ nor $\mu \rho$ are powerful lithologic indicators by themselves, but used in combination can reveal a great deal about lithology

\section{METHOD OF ANALYSIS}

The first approach here was to use single gather modeling to show theoretical AVO responses. In single CMP gather modeling, well logs are often used to construct the geological models. The data from Briga 84 well were used to generate synthetic gathers from 0 to 60 degree angle offset. Most of the sands showed predominantly class III AVO response (Fig. 3). 


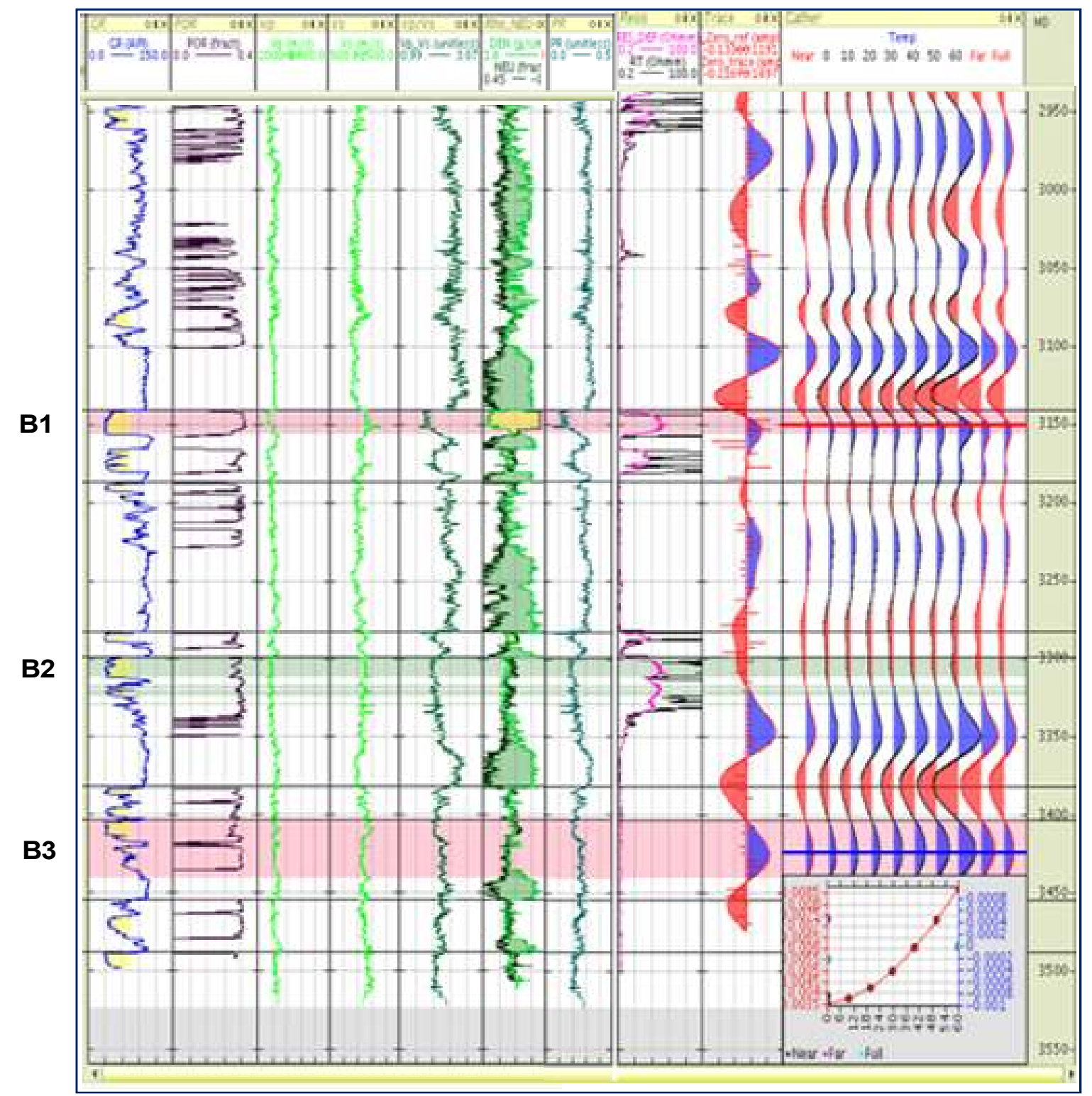

FIG. 3: Briga 84 Zeoppritz Model.

To determine fluid saturation effects, fluid replacement modeling was performed using logs of Briga 84 well. The simple approach to fluid substitution requires blocking the target sand interval (B2 and B3) on the logs and then defining constant rock and fluid properties for this interval. This approach is faster and less complicated than a more detailed petrophysical analysis. The matrix was assumed to be sandstone, water saturation (Sw) was set to $100 \%$, and then the porosity value was adjusted until the matrix density was about $2.65 \mathrm{~g} / \mathrm{cc}$. For the fluid substitution, a Sw=20\% and a likely gas saturation of $80 \%$ based on nearby producers. Also water density $=1.089 \mathrm{~g} / \mathrm{cc}$, water bulk modulus $(K)=2.380 \mathrm{Mpsi}$, gas density $=0.103 \mathrm{~g} / \mathrm{cc}$, gas $\mathrm{K}=0.0208 \mathrm{Mpsi}$, and dry rock Poisson's ratio $=0.12$ were used. These numbers represent widely used empirical values for Class 3 sands. The modeling program then calculated p-wave and s-wave velocity, density, moduli and Poisson's ratio for the gas case based on BiotGassman theory and the parameters listed above. Note that these values are constant over the blocked sand interval. The resulting synthetic gather shows dramatically a progressive increase in amplitude from brine case to gas case (Fig. 4). 


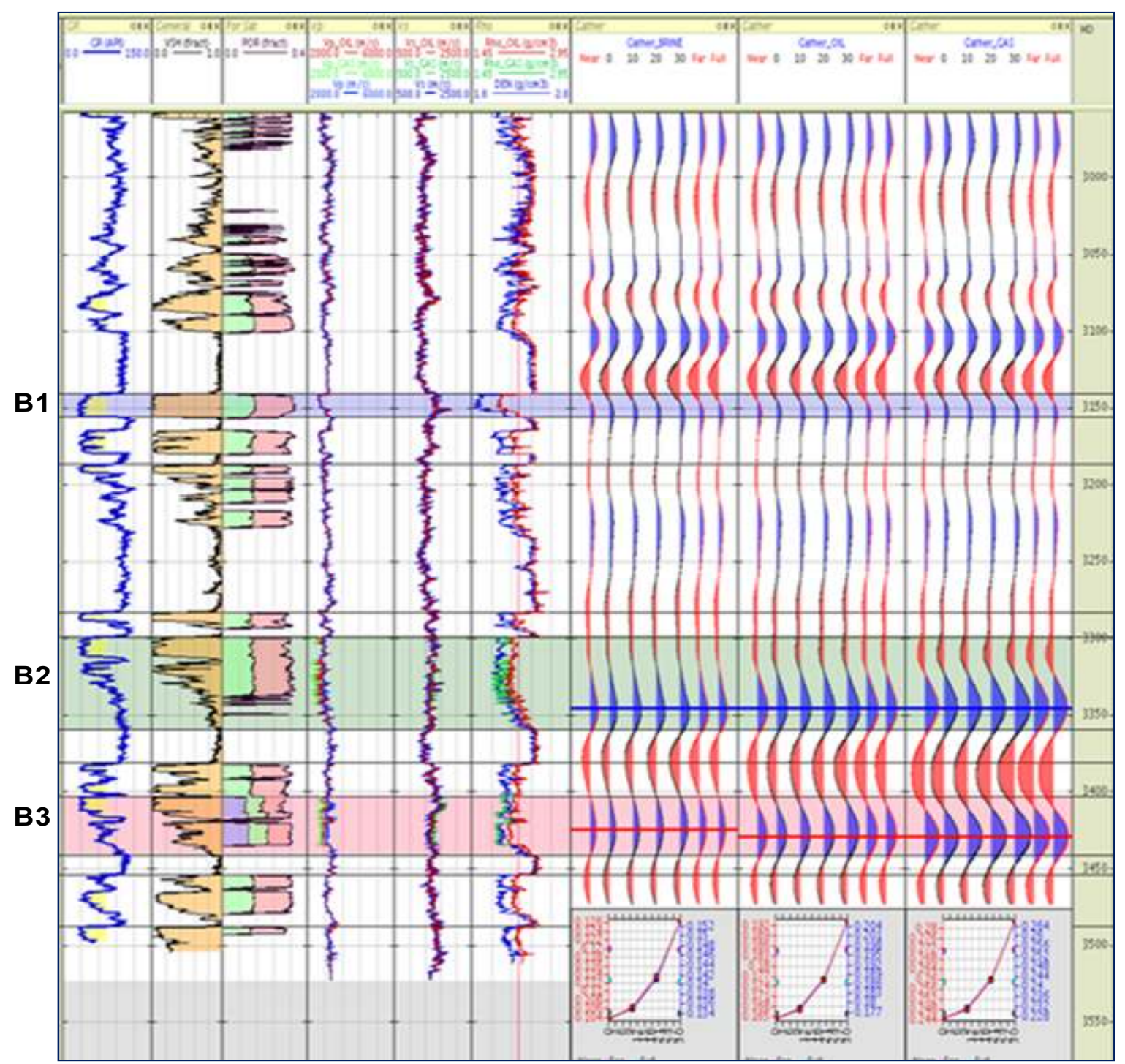

FIG. 4: FRM and Synthetics: B2, B3.

Finally Seismic coloured inversion was used to convert seismic reflectivity data to a relative impedance data set. The coloured inversion operator used to invert the Briga
PSDM (figure 5) was derived by first plotting in a log-log scale, the amplitude spectra 


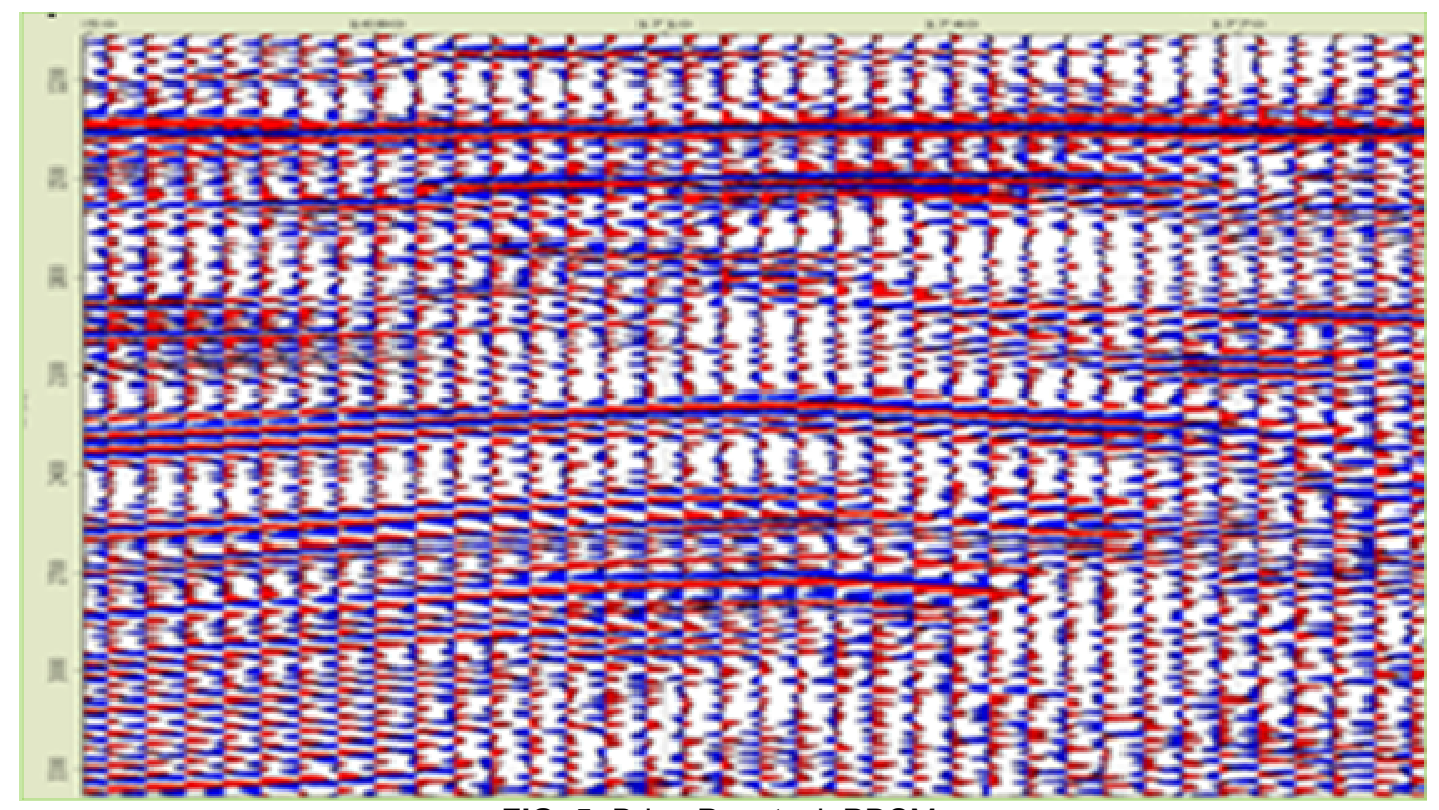

FIG. 5: Briga Pre stack PDSM

Of the Impedance for Briga 84 well. A straight line was fitted into the impedance - frequency field to get the desired output impedance spectrum. The average seismic spectrum was calculated from the set of seismic traces around the well. The operator spectrum was calculated from these two preceding spectra which has the effect of shaping the seismic spectrum to the impedance spectrum with the seismic band. Finally, putting together the derived amplitude spectrum with the -90 degree phase shift produced the Coloured Inversion $(\mathrm{Cl})$ operator which was the applied to all seismic traces.

\section{RESULTS AND DISCUSSION}

Figs.6 shows segments of LambdaRho and MuRho sections at the reservoir.

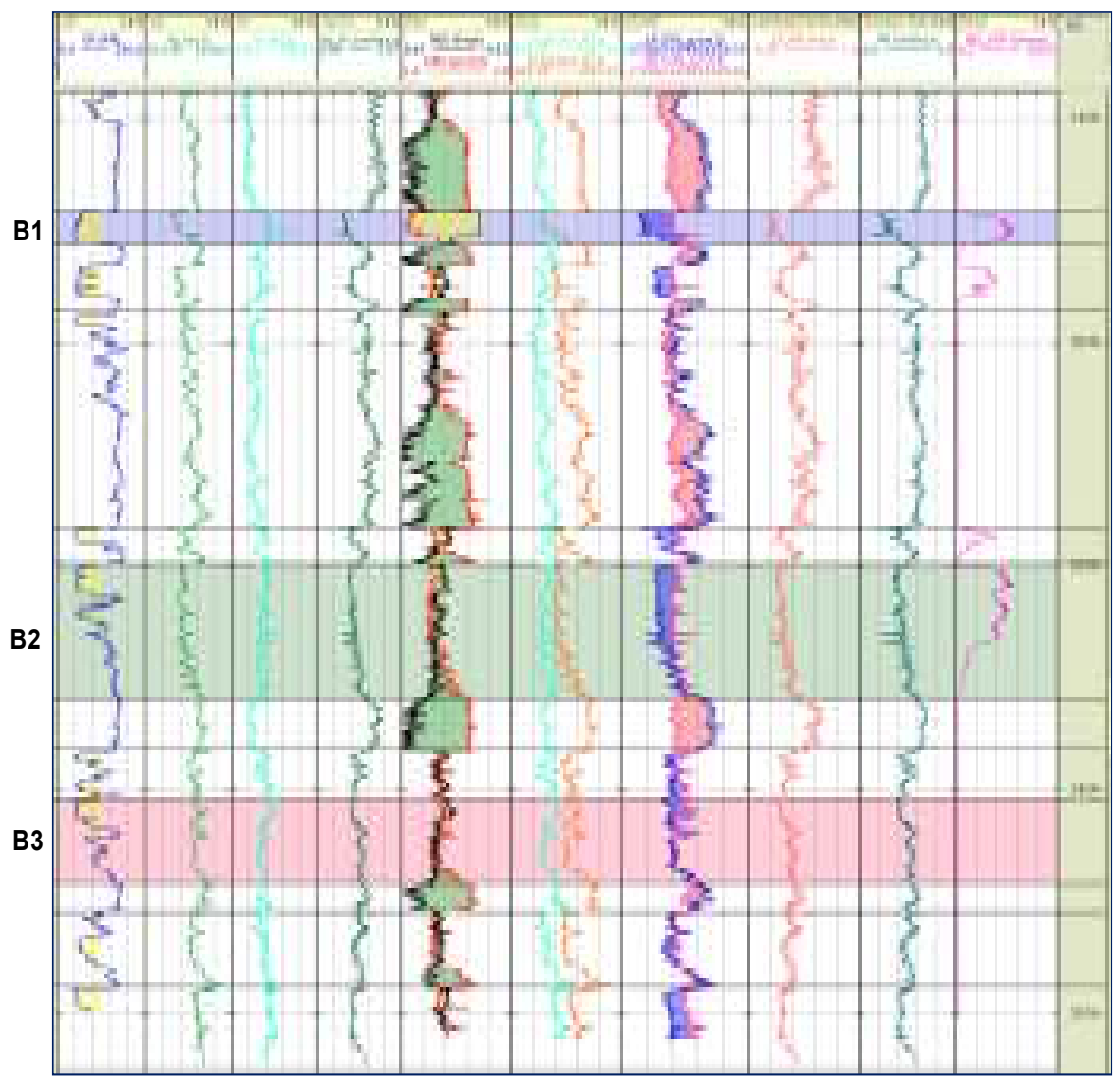

FIG. 6: Estimated logs, Briga 84 well. 
Levels B1, B2, and B3 Relatively low LambdaRho values were observed in porous gas sands. Also, because the acoustic impedance (Al) and shear impedance (SI) share both rigidity and density, the log curves tend to track each other and never cross over (track 6), with only the lowest impedance sand or the highest impedance shale zones being clearly distinguishable. By contrast, the $\lambda \rho$ and $\mu \rho$ curves (track 7) have similar value ranges, that do crossover with $\lambda \rho<$ $\mu \rho$ for gas zones while $\lambda \rho>\mu \rho$ is an indicator of shale breaks. At deeper levels and Low Resistivity Pay (LRP) zone, (B3), the LMR curves also show fairly good crossover.

The Poisson's ratio of sand was less than that of the surrounding shales. (Track 9) This caused an amplitude and/or phase change with offset. In a sand shale system, the above changes with offset are good indicators of presence of sand. A change with offset as described above would not be associated with shale/shale contacts. Figs.7-9 compare the Vp vs Vs; SI vs $A$ l and $\lambda / \rho$ vs $\mu \rho$ multiwell cross plots, with $N \rho$ vs $\mu \rho$ showing a significant advantage in isolating lithologic properties eg sand and shale facies. Both the Vp vs Vs and the $\mathrm{SI}$ vs $\mathrm{Al}$ crossplots are unable to delineate the reservoir but $\lambda \rho$ vs. $\mu \rho$ do. As shown in Fig. 9, the lowest $\lambda / \rho$ point has the best gas sand values along with $\mu \rho$ values higher than shales. The reason for the separation improvement in Fig. 9 compared to Figs.7 and 8 is that the $N / \rho$ vs. $\mu \rho$ axes are orthogonal with regard to Lamés parameters or modulii, unlike Vp vs. Vs or SI vs. Al, thereby making cross plot more discriminating.

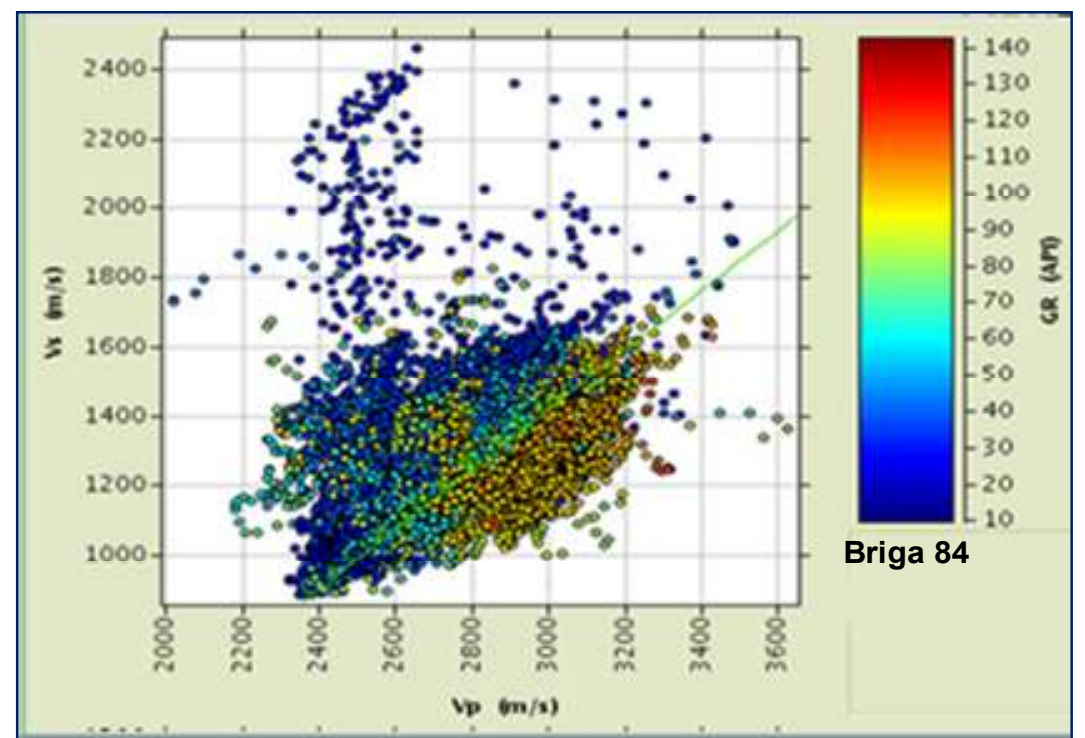

FIG. 7: Multi well cross plot of shear wave velocities (Vs) and compressional wave Velocities (Vp)

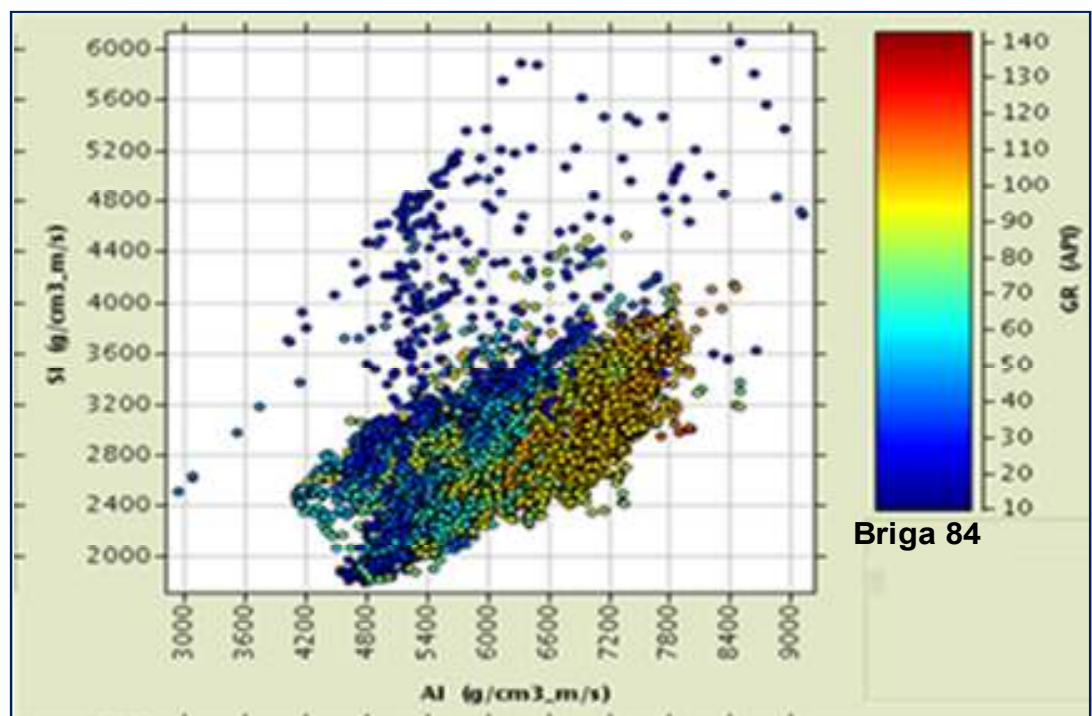

FIG. 8: Multi well cross plot of shear impedance (SI) vs. acoustic impedance.(Al) 


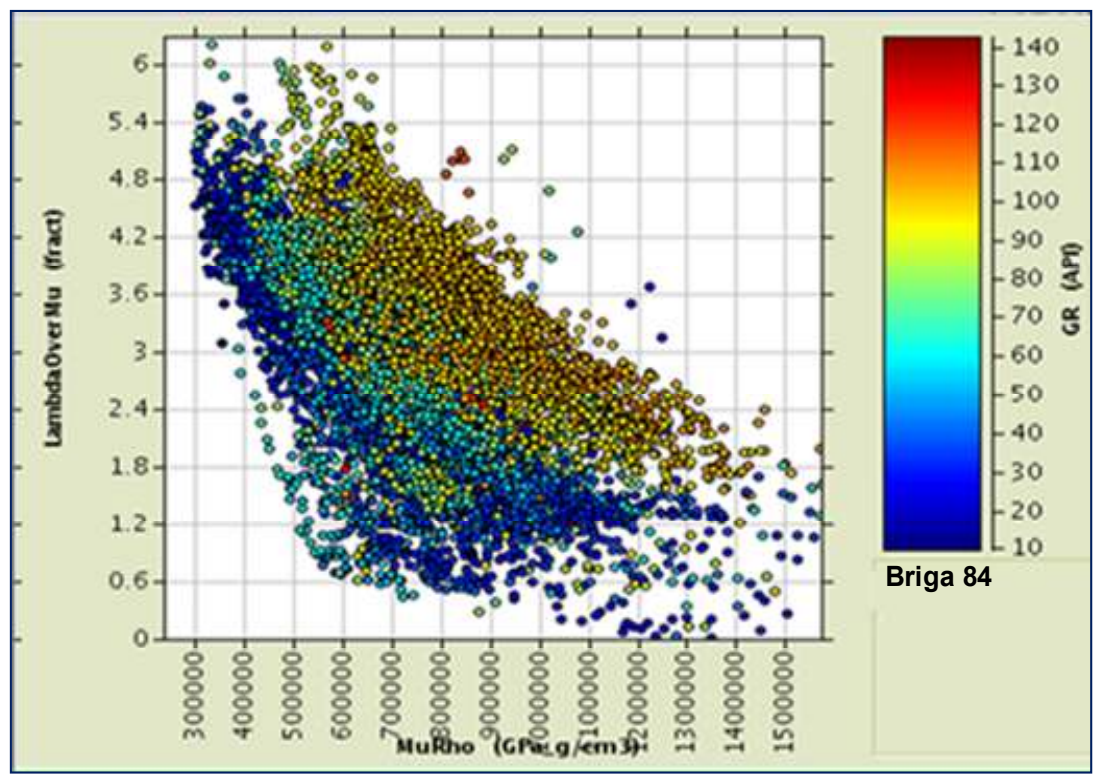

FIG. 9: Multi well cross plot of Lambda over Rho vs. Mu Rho.

Fig.10-12 shows cross plots of $\lambda \rho$ vs. $\mu \rho$ and $\lambda \rho-\mu \rho$ vs. Al for B1 horizon and $\lambda \rho-\mu \rho$ vs. Al for B3 horizon (see Figs.3\&4). Beyond the standard $\lambda \rho$ vs $\mu \rho$ cross-plotting that isolated gas sand clusters in the log (Fg. 10), an improved separation of the high porosity sands into gas, oil and brine was also achieved using $\lambda \rho-\mu \rho$ vs. Al (Fig. 11). Fig. 12 shows $\lambda \rho-\mu \rho$ vs. Al cross plotting could also be used to isolate shale, sandy shale and gas sands.

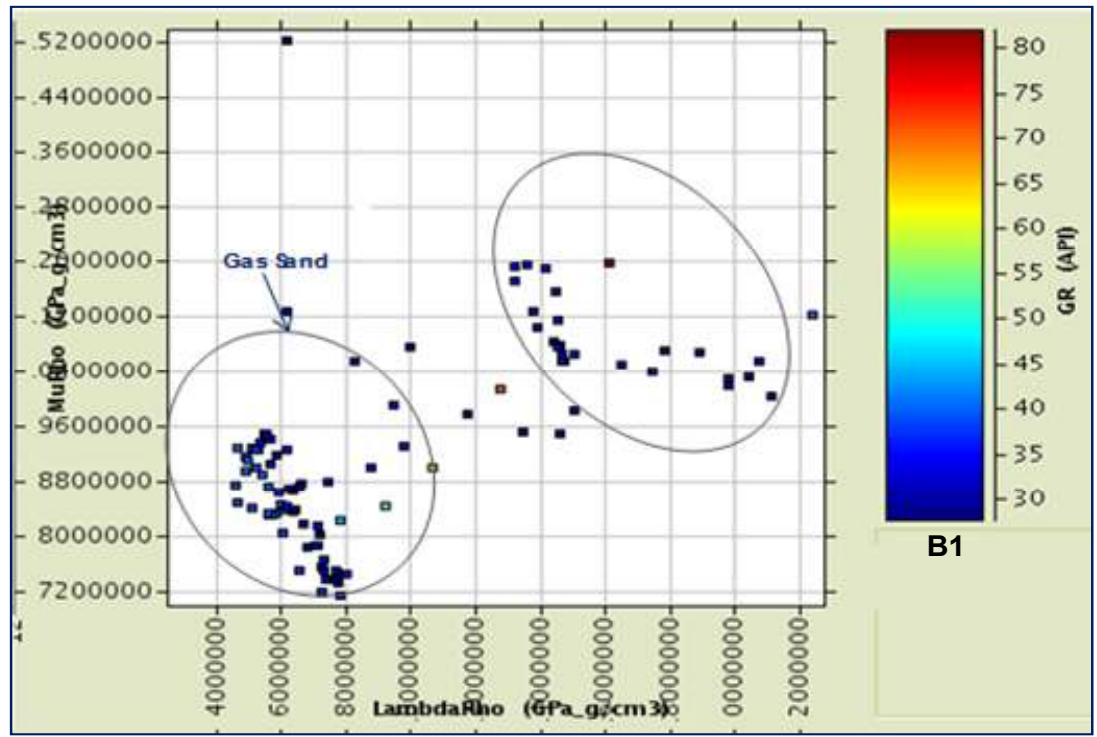

FIG. 10: B1 Lambda Rho Vs Mu Rho Cross plot 


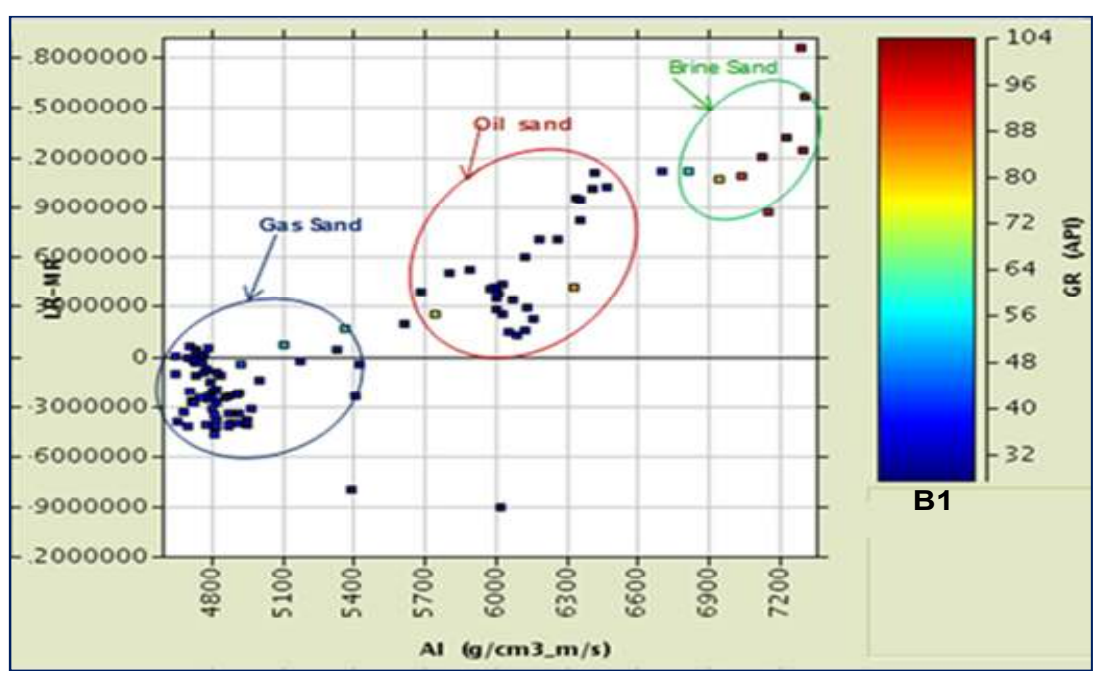

FIG.11: B1 Lambda Rho-Mu Rho Vs Al Cross plot

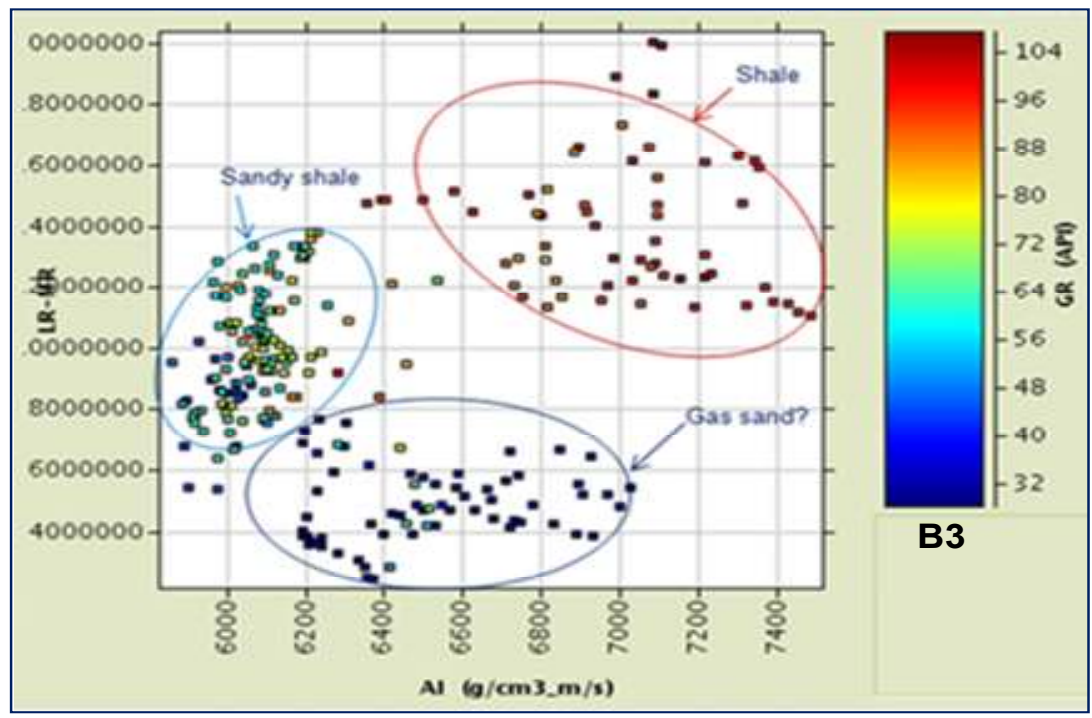

FIG. 12: B3 Lambda Rho - Mu Rho Vs Al Cross plot

The results obtained from different coloured inversions of Briga 84 PSDM pre-stack VT compared in figures 13-15

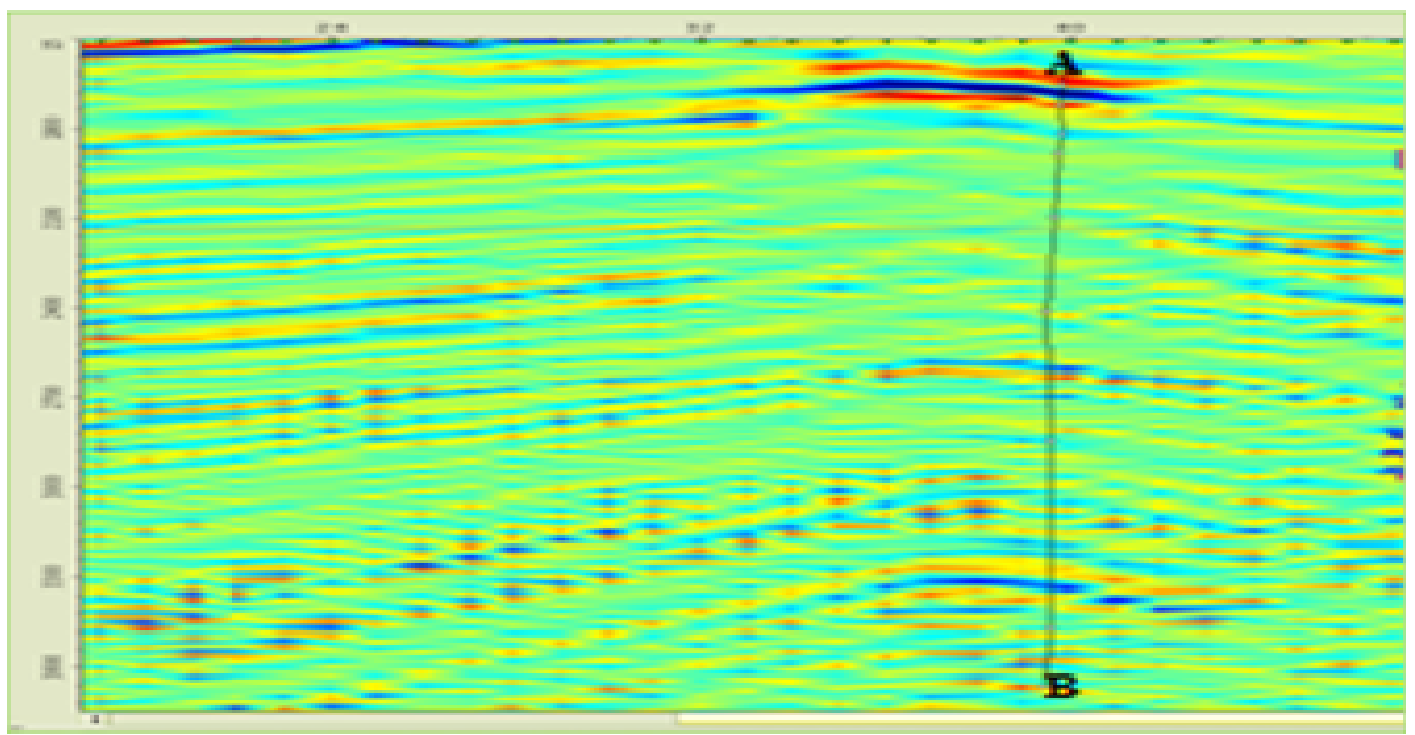

FIG. 13: Al Colored Inversion 


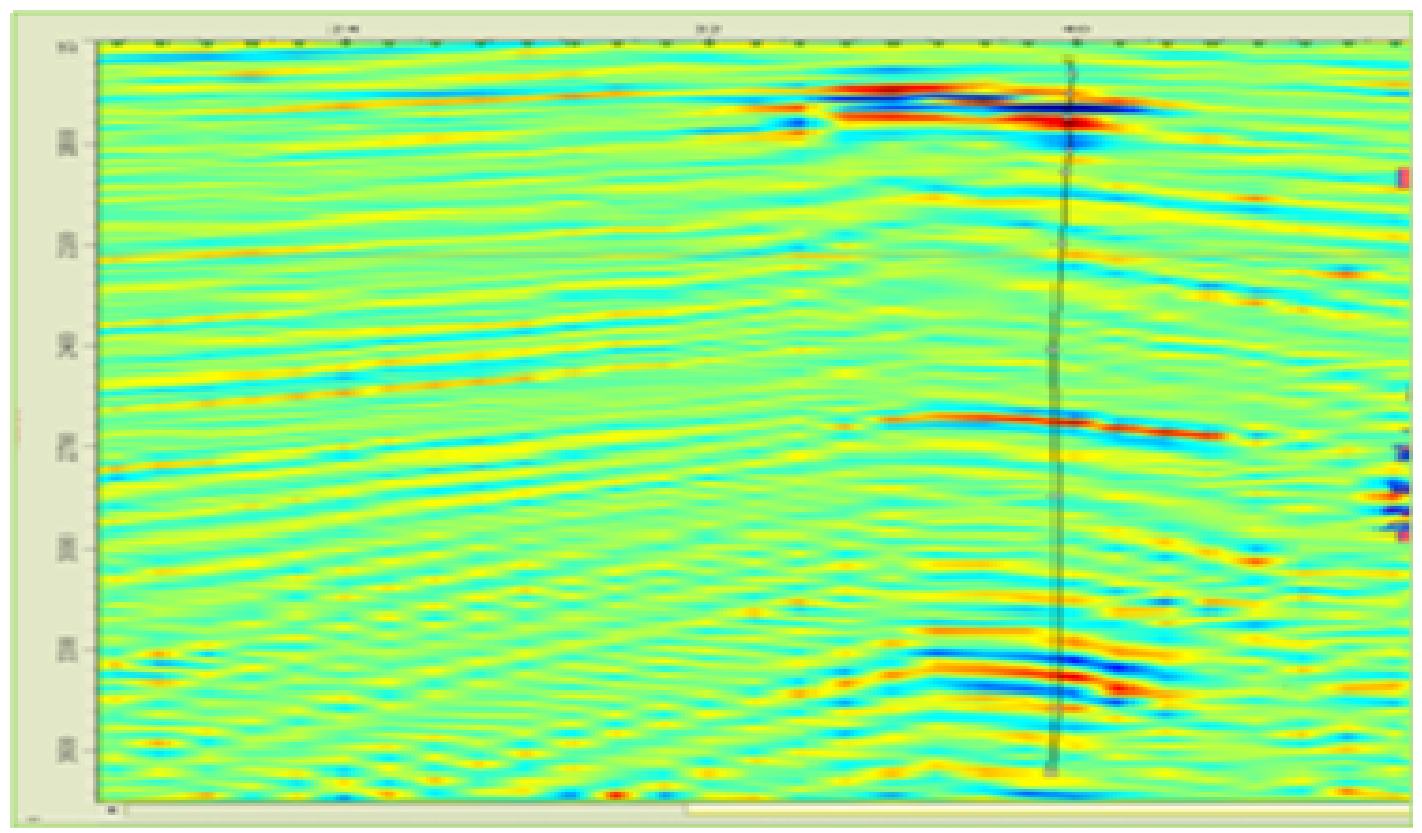

FIG. 14: Mu Rho $(\mu \rho)$ Coloured Inversion

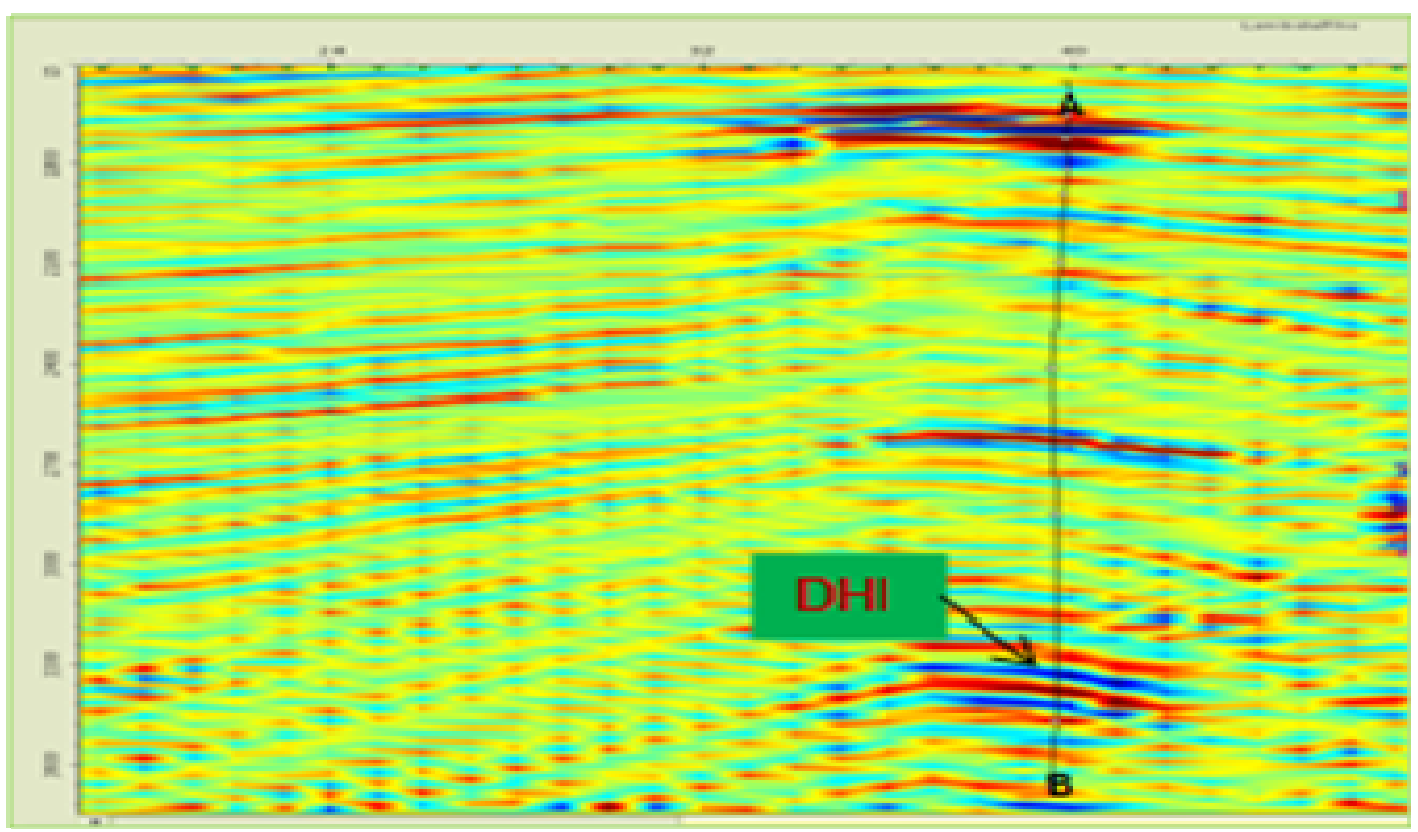

FIG. 15: Lambda Rho $\lambda \rho$ Coloured Inversion (Improved seismic resolution)

The same anomalies are present in all the inverted sections albeit in moderately low colour amplitudes. The Lambda Rho $(\lambda \rho)$ coloured inversion (Figure 15) displays a much improved resolution than the $\mathrm{Al}$ and $\mathrm{Mu}$ Rho ( $\mu \rho)$ coloured inversions. The low amplitude zone (DHI) is correlatable to the anomaly delineated at almost the same depth at $3330 \mathrm{~m}$ (TVDSS) by all the inversion methods.

Therefore, as an exploration tool for hydrocarbon accumulation, the Lambda Rho $(\lambda \rho)$ technique is a good indicator of the presence of low impedance sand encased in shale which are good gas reservoirs The Lambda Rho $(\lambda \rho)$ coloured inversion can be used in conjuction with other direct hydrocarbon indicators such as AVO analysis

\section{CONCLUSIONS}

AVO synthetic gather models constructed along Briga 84 well paths predicted the reservoir sands would produce class three AVO responses, typical of low impedance sands. Also, FRM and porosity substitution work showed that the high porosity gas sands would produce bright, class 3 AVO responses that would clearly distinguish them from brine or gas cases.

The study also revealed that an improved petrophysical discrimination and greater insight in isolating reservoir rock properties for pore fluid and lithology can be achieved using LMR analysis, with LRMR vs. Al cross-plotting showing a better fluid contact and lithologic definition. Therefore, both AVO and LMR 
analysis can be successfully used in mitigating reservoir risk in the study area

\section{ACKNOWLEDGEMENT}

The author is grateful to IKON Corporation for making available the required software for the interpretation of the data sets.

\section{REFERENCES}

Aki, K and Richards, P. G., 1980. Quantitative Seismology. Freeman WH and Co.

Doust, $\mathrm{H}$ and Omatsola, E., 1990. Niger Delta, in, Edwards J D, and Santogrossi, PA, eds., Divergent/passive Margin Basins, AAPG Memoi., (48): 239-248.

Ejedawe, J. E., 1981. Patterns of incidence of oil reserves in Niger Delta Basin. American Association of Petroleum Geologists. (65): 1574-1585.

Evamy, B. D., Haremboure, J., Kamerling, P., Knaap, W. A., Molloy, F. A and Rowlands, P. H., 1978. Hydrocarbon habitat of Tertiary Niger Delta: American Association of Petroleum Geologists Bulletin. (62): 277-298.

Goodway, W., Chen, T and Downton, J., 1997. Improved AVO fluid detection and lithology discrimination using Lame petrophysical parameters; " $\lambda \rho$ ", " $\mu \rho$ ", \& " $\lambda / \mu$ fluid stack", from $P$ and $S$ inversions. 1997 CSEG meeting abstracts. 148-151.

Gray, F. D and Andersen, E. C., 2000. Case histories: 1 Inversion for rock properties. EAGE 62nd Conference and Technical Exposition.

Paul, F., Anderson, F and Gray, D., 2001. Using LMR for Dual Attribute Lithology Identification. SEG expanded Abstracts, San Antonio. 201-202.
Petroconsultants., 1996. Petroleum exploration and production database. Houston, Texas, Petroconsultants, Inc., (database available from Petroconsultants, Inc., P.O. Box 740619, Houston, TX 77274-0619)

Rutherford, S. R and Williams, R. H., 1989. Amplitudeversus-offset variation in Gas Sands. Geophysics. (54): 680-688.

Short, K. C and Stauble, A. J., 1967. Outline of Geology of Niger Delta. American Association of Petroleum Geologists Bulletin. (51): 761-779.

Stacher, P., 1995. Present understanding of the Niger Delta hydrocarbon habitat, in Oti MN, Postma G eds., Geology of Deltas: Rotterdam. Balkema AA, 257-267.

Shuey, R. T., 1985. A simplification of Zeoppritz equations. Geophysics. (50): 609-614.

Tuttle, M. L. W., Charpentier, R. R and Brownfield, M. E., 1999. The Niger Delta Petroleum System: Niger Delta Province, Nigeria Cameroon, and Equatorial Guinea, Africa.USGS Open file report 99-50-H.

Zeoppritz, K., 1919. On the Reflection and Propagation of Seismic Waves. Erdbebenwellen VIIB, Gottiger Nachrichten. (1): 66-84. 